\title{
Evaluation of three fast- and slow-growing chicken strains reared in two production environments
}

\author{
A. Ghayas ${ }^{1 \#}$, J. Hussain ${ }^{1}$, A. Mahmud ${ }^{1} \&$ M.H. Jaspal ${ }^{2}$ \\ ${ }^{1}$ Department of Poultry Production, Faculty of Animal Production and Technology, University of Veterinary and Animal \\ Sciences, Lahore, 54000, Punjab, Pakistan \\ ${ }^{2}$ Department of Meat Science and Technology, Faculty of Animal Production and Technology, University of Veterinary \\ and Animal Sciences, Lahore, 54000, Punjab, Pakistan
}

(Submitted 12 February 2020; Accepted 6 May 2020; First published online 16 June 2020)

Copyright resides with the authors in terms of the Creative Commons Attribution 4.0 South African Licence.
See: http://creativecommons.org/licenses/by/4.0/za
Conditions of use: The user may copy, distribute, transmit and adapt the work, but must recognise the authors and the South African
Journal of Animal Science.

\begin{abstract}
The present study evaluated performance, physiological response and economics of commercial fast growing (CFG), commercial slow growing (CSG), and Rhode Island Red (RIR) chickens under intensive and free-range rearing environments. After 21 days of rearing under the same intensive environment 240 birds from each strain were subjected to free-range and intensive rearing until they were 56 days old. Each treatment was replicated six times with 20 birds in each replicate. Body surface and cloacal temperatures, respiration and heart rates, feed intake, bodyweight and weight gain, feed conversion efficiency, growth efficiency, and liveability were recorded. Significant differences among strains were detected in physiological response and growth performance (except liveability). Rearing environment also caused significant differences in physiological parameters (except body surface temperature) and growth performance (except liveability). Significant interactions of the strains and production systems were detected. The CFG strain grew most rapidly under the intensive system with differences between strains being reduced in the free-range system. The RSG and CSG strains had similar respiration rates under the two production systems but differed significantly from each other. However, the CFG strain had a significantly elevated respiration rate in the free-range system. Total input cost of rearing CFG under the intensive system was highest (\$3.54) among the treatments, whereas CSG under a free-range environment generated the highest profit ( $\$ 0.37$ per bird). In conclusion, rearing CSG under free range was the most economic farming strategy in today's scenario.
\end{abstract}

Keywords: economics, fast-growing, free range, growth, intensive system, physiology, slow-growing rural chickens

\#Corresponding author: 2016-phd-1030@uvas.edu.pk

\section{Introduction}

Since the second half of the twentieth century, the poultry industry has developed rapidly as a specialized cost-efficient sector of animal farming (Bennett et al., 2018; Karcher \& Mench, 2018). Current commercial selection practices in the broiler industry are focusing on increased meat yield, improved feed conversion and rapid growth rate. This has resulted in good early life performance in broilers that have the potential to gain 4.3 to 4.5 times their weight in the first week and 3.5 and 2.5 times in the second and third weeks. However, it has had a negative impact on correlated traits such as welfare (Hiemstra \& Napel, 2013) and disease resistance (Cook, 2000; Julian, 2000). Although efforts are directed at improving productivity, animal welfare organizations are keeping intense focus on promoting the rearing of birds in an environment in which they can enjoy a healthy life. Today's consumers appreciate the products that originate from poultry sanctuaries where the welfare of birds is of good quality ( $\mathrm{Da}$ Silva et al., 2017). There are causal relationships between environmental factors, behaviour and morphological changes in poultry, which can be helpful in making recommendations for the practice by experimental modification of the rearing environment and behaviour (Thaxton et al., 2016).

Slow-growing broilers have been introduced in the poultry industry to mitigate the issues that surfaced with fast-growing broilers. These slow-growing broilers have a significantly lower growth rate than the current industry average of 61 grams per day, which means birds need to stay on the farm significantly longer to 
reach the same market weight (National Chicken Council, 2017). Initially, breeding of slow-growing birds was carried out only by French breeding companies (e.g. Sasso, Sabres, France) (Chabault et al., 2012). Today several companies are involved in this business, such as Grimaud Freres Selection (Sevremoine, France), Aviagen Group (Huntsville, Alabama, USA) and Cobb-Vantreas (Siloam Springs, Arkansas, USA) (Damme et al., 2015). Currently, slow-growing broilers make up a tiny percentage of the market in the United States, but they have gained a foothold in parts of Europe, making up to $25 \%-30 \%, 15 \%$, and $7 \%$ of total broiler production in The Netherlands, France, and the United Kingdom, respectively (Thornton, 2016). Recently, CobbSasso were introduced in Pakistan with three crossbreeds, from which CobbSasso-T88 has developed a good reputation among the general public and small-scale farmers, but the question of better welfare among the strains still exists.

Rural chickens of Pakistan are also considered slow-growing birds (Batool et al., 2018; Hussain et al., 2018). Several breeds are reared as rural backyard poultry, such as Aseel, Desi (nondescript), Fayoumi and RIR. Rhode Island Red chickens can be fruitful as an alternative genotype for rural poultry farmers on a small scale who cannot afford environmentally controlled poultry houses because they can be managed easily as a free-range bird (Sadef et al., 2015). Slow growth is a major hurdle in the propagation of rural poultry strains on a larger commercial scale (Hussain et al., 2018). Rhode Island Red chickens are thought to be highly adaptive to harsh climatic conditions, but there is a paucity of scientific information about early growth and welfare compared with commercial fast- and slow-growing strains. Therefore, the present study was planned to compare the physiological response, growth performance, and economic aspects of three strains (CFG, CSG, and RIR) under intensive and free-range rearing environments.

\section{Materials and Methods}

The present study was approved by the Animal Ethics Committee of the Office of Research Innovation and Commercialization in UVAS, No. DR/986, dated 18 September 2018. It was conducted at the Avian Research \& Training Centre (ARTC), Department of Poultry Production, University of Veterinary \& Animal Sciences (UVAS), Lahore, Pakistan during a period of eight weeks. The geographical coordinates of ARTC are $31^{\circ} 24^{\prime} 36.90^{\prime \prime} \mathrm{N}$ and ${ }^{\circ} 22^{\prime} 31.33^{\prime \prime} \mathrm{E}$, at an altitude of $211 \mathrm{~m}$. The outdoor environment, temperature and humidity levels were recorded daily with a wet and dry bulb hygrometer (Mason's type, Zeal, England) (Figure 1).

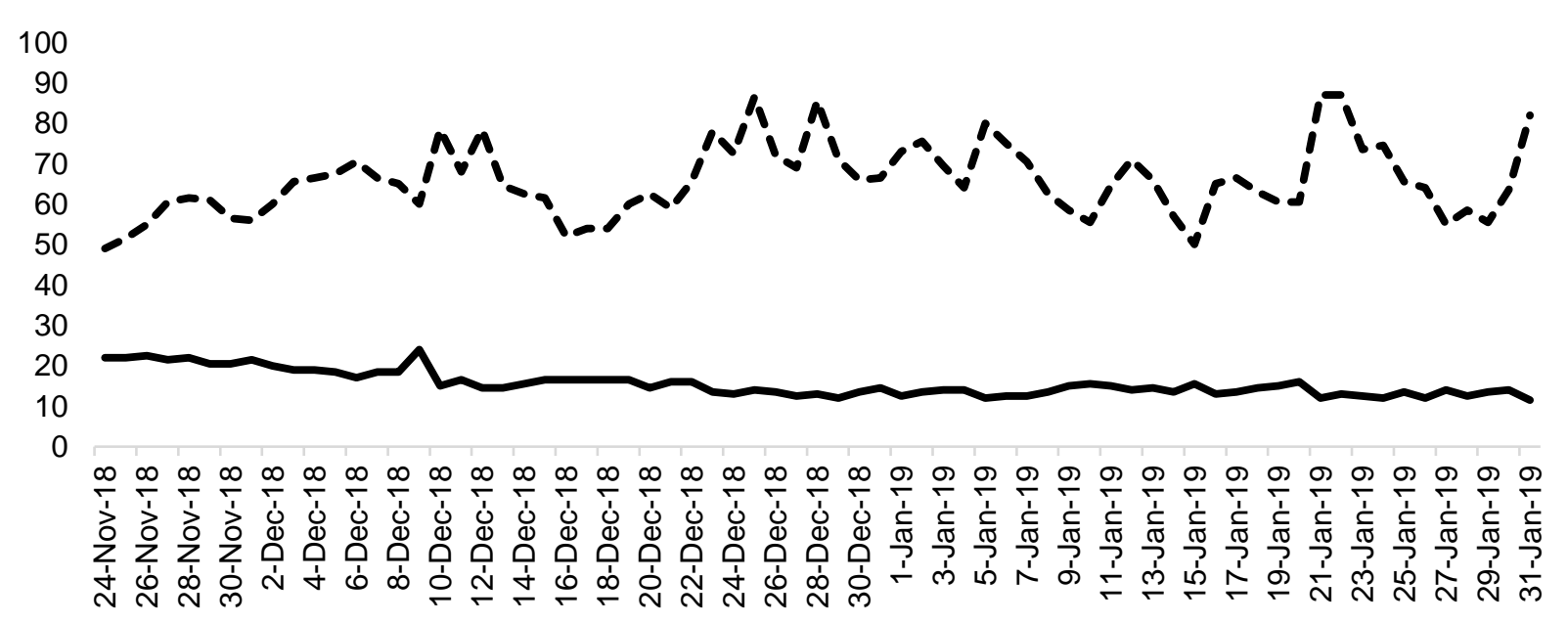

$$
\text { Temperature }\left({ }^{\circ} \mathrm{C}\right) \quad \text { - }- \text { Humidity (\%) }
$$

Figure 1 Temperature $\left({ }^{\circ} \mathrm{C}\right)$ and humidity (\%) during the experimental period

Two hundred forty CFG, CSG and RIR chicks (in total 720 chicks) were procured from commercial sources, subjected to brooding for one week, and allowed to grow in an intensive deep-litter floor system for 21 days. From day 22, the chicks from the three strains were randomly distributed in a $3 \times 2$ factorial design of two production systems (intensive deep-litter floor and free-range system). Each treatment was replicated six times with 20 birds/replicate. The intensive production system provided $0.06 \mathrm{~m}^{2}$ of floor space per bird. Guidelines of USDA were followed for the free-range system, which allowed the birds no special facilities 
except for an outdoor area and an indoor house as shelter. For this, a pen measuring $1.11 \times 0.93 \mathrm{~m}$ indoor area ( $0.05 \mathrm{~m}$ per bird) and $6.01 \times 0.93 \mathrm{~m}$ for outdoor access were provided to 20 birds.

In the brooding house they were provided with a heating source to keep the room temperature at the required level. For the first three days, the temperature was maintained at $95{ }^{\circ} \mathrm{F}\left(35^{\circ} \mathrm{C}\right)$ then gradually decreased until it reached $75^{\circ} \mathrm{F}\left(24^{\circ} \mathrm{C}\right)$. The relative humidity percentage was maintained between $60 \%$ and $65 \%$. A commercial broiler starter diet was offered to all treatments during the first week and a grower ration was provided in the later period till the 56th day. Ad libitum feed and water were offered in manual feeders and drinkers without compromising the space requirement. Feed composition is shown in Table 1. The chicks were vaccinated against Infectious Bronchitis (IB) and Newcastle Disease (ND) on day 1. Later, vaccination was performed against IB (on day 12) and ND (on days 3, 7, and 17). Each genotype was reared in a separate house and pens.

Table 1 Feed composition of experimental birds during the starter and grower phases

\begin{tabular}{lrc}
\hline Ingredients & Starter $(\mathrm{g} / 100 \mathrm{~g})$ & Grower $(\mathrm{g} / 100 \mathrm{~g})$ \\
\hline Corn & 55.65 & 58.37 \\
Soybean meal 44\% & 30.72 & 27.24 \\
Canola meal & 10.00 & 6.00 \\
Sunflower meal & 0 & 1.60 \\
Calcium carbonate & 1.21 & 1.27 \\
Monocalcium phosphate & 0.56 & 0.61 \\
*Premix & 0.50 & 0.50 \\
Vegetable oil & 0.32 & 3.27 \\
Lysine sulphate & 0.30 & 0.33 \\
DL Methionine & 0.27 & 0.27 \\
Salt & 0.20 & 0.14 \\
Soda bicarb & 0.19 & 0.31 \\
L-Threonine & 0.07 & 0.08 \\
Phytase 10000 & 0.01 & 0.01 \\
Composition & & \\
Crude protein (\%) & 22.48 & 20.05 \\
Metabolizable energy Kcal/Kg & 2800 & 3025
\end{tabular}

Premix contained vitamin A: 9000 I.U; vitamin D3: 3250 I.U; vitamin E: 30 I.U; vitamin K3: 4 mg; thiamine: 3.5 mg; riboflavin: $8 \mathrm{mg}$; vitamin $\mathrm{B}_{6}: 4.4 \mathrm{mg}$; vitamin $\mathrm{B}_{12}: 1.5 \mathrm{mg}$; folic acid: $1 \mathrm{mg}$; vitamin $\mathrm{B}_{5}$ calcium-D-pantothionate: $12 \mathrm{mg}$; niacin: $55 \mathrm{mg}$; biotin: $5 \mathrm{mg}$; choline chloride: $700 \mathrm{mg}$; selenium: $50 \mathrm{mg}$; zinc: $110 \mathrm{mg}$; copper: $67.2 \mathrm{mg}$; iron: $394 \mathrm{mg}$; manganese: $172 \mathrm{mg}$; potassium iodide $0.8 \mathrm{mg}$; furazolidone $100 \mathrm{mg}$; maduramicin:50 mg

Physiological responses were monitored with body surface temperature (BST), Cloacal temperature (CT), and heart and respiration rates (HR and RR, respectively). Surface temperatures $\left({ }^{\circ} \mathrm{C}\right)$ of various body regions were recorded with a non-contacted infrared thermometer (Fluke UT-932, USA) held 15 centimetres from the body. Mean BST was calculated with the formula:

$$
T_{m s}=0.03 T_{h}+0.70 T_{b}+0.15 T_{s}+0.12 T_{w}(\text { Richards, 1971) }
$$

Where: $\quad T_{m s}=$ mean BST,

$T_{h}=$ temperature of the head,

$T_{b}=$ temperature of the back,

$T_{s}=$ temperature of the shanks, and

$T_{w}=$ temperature of the wings.

Cloacal temperature $\left({ }^{\circ} \mathrm{C}\right)$ was recorded with a Medicare digital translucent thermometer with an alarm signal (Product \# 693966390034, MANA \& Co, Pakistan). The thermometer was inserted in the cloaca of the 
birds to a depth of three centimetres until the alarm signal and meter reading become static. Heart rate was measured with a stethoscope $\left(3 \mathrm{M}^{\mathrm{TM}}\right.$ Littman $\odot$ Classic, Illinois, USA), while the time was counted on a stopwatch (Mutibvu et al., 2017). The respiration rate was recorded by holding the birds in an inverted position and observing the abdominal movements for one minute (Mutibvu et al., 2017). All measurements were taken two times a day at 09:00 and 17:00 to minimize environmental variations. In a week, physiological responses were recorded for three days on an alternate basis and then the data were converted to a mean to obtain an average for the week.

Performance was measured by feed intake (FI), final body weight (FBW), weight gain (WG), growth efficiency $(F C E)$, and liveability. Feed intake $(F I)$ was recorded daily by subtracting the measured refused amount of feed from the amount that was offered. Daily FI data were summed to calculate weekly FI. The weight of each replicate was recorded weekly and with the differences between the weekly measures being WG. Measurements of weights (feed or bird on whole replicate basis) were made on a digital weighing balance bench scale (Gromy Industry Co., Ltd, China) (least count $0.01 \mathrm{~g}$ ). Feed conversion efficiency (FCE) was estimated by dividing the WG by FI (only commercial FI, without pasture intake) (Berhe \& Gous, 2008). Growth efficiency was calculated by dividing the WG over a period of time by the initial weight following Gondwe and Wollny (2003). Liveability was calculated in percentage by deducting the mortality from total placed birds and dividing this value by total placed birds.

At the end of the trial, an economic analysis was performed. Cost per bird was the sum of the prorated costs, including chick cost, feed expenditure, costs of bedding material, labour, vaccination and medication and miscellaneous costs (bulb replacement, repairing faulty instruments and others). The value of each bird was the selling price of the replicate divided by the FBW of the birds to calculate income per bird. Profit was the difference between income and cost.

The data were arranged in Microsoft Excel and analysed in Statistical Analysis Software $\left(\mathrm{SAS}^{\circledR}, 9.1\right.$ version, USA). A two-way factorial analysis was performed by assigning strains and production systems as main effects. The means were separated with Tukey's HSD test at a significance level of $P \leq 0.05$. The following mathematical model was used:

$$
Y_{i j k}=\mu+s_{i}+p_{j}+(s p)_{i j}+e_{i j k}
$$

Where: $Y_{i j k}=$ observation of the dependent variable recorded on ith genotype and jth production system in the kth replicate,

$\mu=$ overall population mean,

$s_{i}=$ effect of ith strain $(\mathrm{i}=3)$ (CFG, CSG, RIR),

$p_{j}=$ effect of $\mathrm{jth}$ production system $(\mathrm{j}=2)$ (intensive system, free-range) $(s p)_{i j}=$ interaction between the ith strain and jth production system, and

$e_{i j k}=$ residual error, $\mathrm{NID} \sim 0, \sigma^{2}$.

\section{Results and Discussion}

Body surface temperature (BST) was differed significantly among the strains (Table 2). The CFG had higher BST than CSG chickens. It is reported that BST is affected significantly by the presence of feather cover on body parts. Featherless areas can result in higher BST (Damane et al., 2018). Since the CFG broilers grow rapidly, they often show poor feather cover compared with CSG. this could be the reason for the higher temperature. Additionally, previous studies showed that the differences in broiler BST, are associated with the thermoregulatory system and that physiological changes occur when homeothermy is affected (Cangar et al., 2008; Yahav et al., 2005). The low feather cover in CFG birds resulted in a greater struggle to maintain their body thermoregulatory system and generate heat, whereas the thermoregulatory system was stable in CSG. However, production system did not affect $(P>0.05)$ BST (Table 2). The interaction between production systems and strains was also not significant $(P>0.05)$.

Significant differences among stains were observed for CT (Table 2). The RIR birds had the highest CT, followed by CSG, and the lowest CT was noted in CFG. Since the growth rates of the experimental strains were different, it seems that the variation in CT may reflect their genetic background for growth. Variations in growth rate are a factor in physiological response in poultry. In the current findings, RIR chickens were lighter and more active (data not presented), whereas CSG and CFG were heavier, thus supporting previous results that lighter weight birds have higher rectal temperature (Tickle et al., 2018). Additionally, heat production per unit body weight by chickens has been found to decrease as birds became heavier (McNab, 1966; Bell \& Weaver, 2002). 
Table 2 Physiological response of fast- and slow-growing strains in intensive and free-range rearing environments

\begin{tabular}{|c|c|c|c|c|}
\hline Treatment & $\mathrm{BST}\left({ }^{\circ} \mathrm{C}\right)$ & CT $\left({ }^{\circ} \mathrm{C}\right)$ & RR (breaths/min) & $\mathrm{HR}$ (beats/min) \\
\hline \multicolumn{5}{|c|}{ Strain } \\
\hline CFG & $35.38 \pm 0.06^{\mathrm{a}}$ & $41.43 \pm 0.04^{c}$ & $61.94 \pm 4.82^{\mathrm{a}}$ & $334.50 \pm 2.50^{c}$ \\
\hline CSG & $35.18 \pm 0.04^{b}$ & $41.70 \pm 0.03^{b}$ & $43.92 \pm 0.57^{b}$ & $353.52 \pm 6.07^{b}$ \\
\hline RSG & $35.29 \pm 0.04^{\mathrm{ab}}$ & $42.01 \pm 0.07^{a}$ & $32.46 \pm 1.01^{\mathrm{c}}$ & $387.60 \pm 7.46^{a}$ \\
\hline \multicolumn{5}{|c|}{ Environment } \\
\hline Intensive & $35.28 \pm 0.04$ & $41.62 \pm 0.07^{b}$ & $40.33 \pm 4.64^{b}$ & $346.92 \pm 7.55^{\mathrm{b}}$ \\
\hline Free range & $35.28 \pm 0.04$ & $41.81 \pm 0.07^{\mathrm{a}}$ & $51.88 \pm 1.56^{\mathrm{a}}$ & $370.16 \pm 5.15^{a}$ \\
\hline \multicolumn{5}{|c|}{ Genotype $\times$ environment interaction } \\
\hline CFG $\times$ intensive & $35.38 \pm 0.08$ & $41.29 \pm 0.03^{e}$ & $46.11 \pm 0.53^{b}$ & $328.10 \pm 2.25^{\mathrm{e}}$ \\
\hline CSG $\times$ intensive & $35.18 \pm 0.03$ & $41.63 \pm 0.03^{c d}$ & $42.92 \pm 0.72^{b}$ & $347.33 \pm 9.30^{d c}$ \\
\hline $\mathrm{RIR} \times$ intensive & $35.18 \pm 0.03$ & $41.48 \pm 0.09^{\mathrm{ab}}$ & $38.17 \pm 1.82^{\mathrm{c}}$ & $365.33 \pm 6.31^{b}$ \\
\hline$C F G \times$ free range & $35.38 \pm 0.08$ & $41.57 \pm 0.03^{d}$ & $77.78 \pm 1.28^{\mathrm{a}}$ & $340.90 \pm 2.46^{\mathrm{de}}$ \\
\hline$C S G \times$ free range & $35.18 \pm 0.03$ & $41.76 \pm 0.03^{b c}$ & $44.92 \pm 0.72^{b}$ & $359.70 \pm 7.76^{\mathrm{bc}}$ \\
\hline $\mathrm{RIR} \times$ free range & $35.29 \pm 0.03$ & $42.09 \pm 0.12^{\mathrm{a}}$ & $32.94 \pm 1.51^{\mathrm{C}}$ & $409.87 \pm 2.55^{\mathrm{a}}$ \\
\hline \multicolumn{5}{|c|}{$P$-values } \\
\hline Genotype & 0.0113 & $<.0001$ & $<.0001$ & $<.0001$ \\
\hline Environment & 0.9613 & 0.0007 & $<.0001$ & 0.0157 \\
\hline Interaction & 0.0939 & $<.0001$ & $<.0001$ & $<.0001$ \\
\hline
\end{tabular}

Letters a-e within a column show significant differences $(P<0.05)$

CFG: commercial fast growing, CSG: commercial slow growing, RIR: Rhode Island Red

BST: body surface temperature, CT: cloacal temperature, RR: respiration rate, HR: heart rate

The interaction effect of strain and production system on CT was also significant (Table 2). Under freerange management, the CT of RIR was significantly higher than either CFG or CSG. However, under the intensive management system the CSG birds had the highest CT, with the RIR being intermediate between them and the CFG birds. The CT of the CSG strain was little affected by production system. However, fastgrowing CFG and the RIR had increased CT in free range relative to the intensive indoor rearing system. The significant interaction implies that genetic potential alone cannot explain differences in CT and that the production environment needed to be considered simultaneously. The RIR, as medium size bird, is considered to be hyperactive and better acclimatized to free range environment, hence, demonstrated higher cloacal temperature. It is possible that higher metabolic rate of CSG and CFG birds made them efficient convertor of nutrients into muscle mass, in addition, intensive system did not allow them to expend their energy on activity and ultimately increased their cloacal temperature.

Differences among strains had a highly significant impact on RR (Table 2). The RIR chickens had the lowest rate with the CSG strain intermediate between them and the CFG strain. Similar to the current results, the RR was significantly different among three strains reared under the extensive system (Mutibvu et al., 2017). The CFG were under stress and were trying to accommodate to the environment. These birds were struggling to adjust their faster growth and excessive metabolic heat production. To reduce metabolic heat stress, broilers rely on panting and increased respiration (Etches et al., 2008). Additionally, oxygen is required in larger amounts with quick delivery at terminal stages of broiler production. On the other hand, slow-growing chickens (both CSG and RIR) were more comfortable than CFG owing to their slower growth rate. Lighter birds tend to be more active than heavier ones. Hence, their respiration rates may vary.

The environmental rearing systems also produced significant variation in RR of the birds. The birds had lower RR in the intensive indoor system compared with free range system. Similar to the current results, Mutibvu et al. (2017) reported a higher RR in birds kept in a free-range environment compared with those in an intensive production system. The activity level in the production system has a role in altering the physiology of the birds and hence can affect the respiration rate. Physical activities such as walking, running, and aggression are higher when birds are in a free-range environment and can these activities can lead to 
more rapid breathing. Additionally, housing conditions, such as accumulation of noxious gases, humidity, and air speed can play a role in modulating the RR of the birds (Li et al., 2017). Regarding the interaction of strain and production environment, it was surprising that the RIR and CSG performed similarly under the two systems but differed significantly from each other. On the other hand, CFG had a significantly elevated RR when kept in the free-range environment compare to when it was kept in the intensive system.

Strains differed significantly in heart rate (Table 2). The highest HR was recorded in RIR, followed by CSG, and was lowest in CFG. Mutibvu et al. (2017) reported significant variation in the HR of three strains when raised under an extensive environment. Recent literature lacks information about HR differences among the genotypes, but an earlier study indicated growth rate and body mass are negatively associated with HR (Muller \& Carroll, 1966). In the present study, CFG had a lower HR, whereas CSG had a comparatively higher rate, but lower FBW. Further, the RIR chickens grew most slowly and had the highest HR. The CSG reportedly has a better myocardial capillary supply and better aortic mechanical properties than genetically selected fast-growing broilers (Harash et al., 2019). Thus, fast-growing broilers may be more prone to cardiopulmonary issues than slow-growing layers and native chickens (Hassanzadeh et al., 2005).

Production system had a significant impact on the heart rate of the birds, with the HR of the birds being generally higher in the free-range environment than under intensive rearing. The statistical analysis showed a significant interaction between genotype and production system. This interaction reflected changes in the magnitude of difference between strains in the two environments, but not changes in their rank order. Olkowski (2007) reported that fast-growing broilers raised on full feed in an intensive environment could reduce their HR more effectively than feed-restricted slow-growing ones. Additionally, Machida and Aohag (2001) found the HR/BW ratio was greater in free-living birds than those that were less active. Here, the CFG had the greatest BW and spent most of their time lying and resting. These factors presumably led to their having a lower HR and HR/BW ratio.

Means for the performance traits are shown in Table 3. The CFG strain had the greatest FI throughout the experiment, followed by CSG, and the lowest FI was noted for the pens of RIR chickens. Commercial fast-growing broilers were previously reported to consume significantly more feed than slower growing Kabir and Leghorn broilers (Branciari et al., 2009). Higher FI in CFG might be because of its genetic characteristic of being growth efficient. Thus, these birds need more feed than RIR which have had less selection pressure for increased growth.

Production system also affected FI significantly. Feed intake was significantly higher in intensive rearing compared with the free-range system, though food consumed through foraging was not included. Similar findings were recorded by Ipek and Sozcu (2017), who reported a significant effect of production system on cumulative $\mathrm{FI}$, with significantly higher consumption in the indoor birds than those that had outdoor access. The differences in FI of the birds under different production systems can be attributed to inherent variables, because in the free-range system birds are exposed to factors such as light intensity and photoperiod, and nutrients such as forages, insects and worms on pasture. Additionally, free-range birds were not provided with commercial feed the time they were outdoors, which resulted in more economical rearing. Contrary to the current results, Li et al. (2017) stated an indoor floor system and free range did not differ in terms of $\mathrm{FI}$.

The interaction between strains and rearing systems was highly significant $(P \leq 0.001)$ reflecting changes in the magnitude of difference between strains in the two environments, but not changes in their rank order. When CFG were reared under the conventional intensive system, they consumed more feed than other strains under intensive and free-range systems. The lowest FI was observed in RIR birds raised in free range. Branciari et al. (2009) also observed higher FI of commercial broilers when reared under intensive systems than slower growing birds under an organic system. In another study, significant genotype and environment interaction was noted that fast-growing broilers had higher FI than local Tanzanian chicken (Ali et al., 2000). In short, the present findings confirm previous reports, which described that the growth rate of the birds made a difference to feed consumption.

The WG and FBW were greater for CFG than CSG and RIR with the latter two strains also differing ( $P$ $<0.0001)$ across both production environments. Hoan and Khoa (2016) described Sasso chickens as slowgrowing birds and lighter in weight than fast-growing commercial broilers (824 vs 2123 grams at 49 days old). Although RIR chickens were lightest among the strains at 56 days old their FBW was greater than the 514-gram body weight observed by Khawajaa et al. (2012) at the same age. Previous studies agree with the current results and describe significantly higher FBW of fast-growing broilers than slow-growing ones that are reared in the same environments (Cömert et al., 2016; Koomkrong et al., 2015; Mikulski et al., 2011). Younis et al. (2016) also observed higher FBW in CFG than in CobbSasso-T44 broilers. The higher weight of CFG in the current study can be attributed to its high genetic potential as a commercial fast-growing genotype whereas CSG is considered less efficient (Younis et al., 2016). Probably the RIR genotype was least efficient in this experiment. 
Table 3 Performance of fast- and slow-growing broiler strains in intensive and free-range rearing environments

\begin{tabular}{|c|c|c|c|c|c|c|c|}
\hline & $\begin{array}{c}F I, g \\
\text { weeks } 4-8 \\
\end{array}$ & $\begin{array}{c}\mathrm{Fl}, \mathrm{g} \\
\text { weeks } 1-8\end{array}$ & FBW, g & $\begin{array}{c}\text { WG, g } \\
\text { weeks } 4 \text { - } 8\end{array}$ & $\begin{array}{l}\text { FCE, g/kg } \\
\text { weeks } 4-8\end{array}$ & $\begin{array}{c}\mathrm{GE}, \mathrm{g} / \mathrm{g} \\
\text { weeks } 1-8\end{array}$ & LIV, \% \\
\hline \multicolumn{8}{|l|}{ Strain } \\
\hline CFG & $5184.42^{a} \pm 262.49$ & $6273.33^{a} \pm 263.28$ & $3405.92^{a} \pm 140.41$ & $2590.75^{a} \pm 140.22$ & $498.82 \pm 3.82^{a}$ & $3.18 \pm 0.17$ & $92.92 \pm 0.96$ \\
\hline CSG & $3833.92^{b} \pm 203.87$ & $4494.53^{b} \pm 203.88$ & $1781.33^{b} \pm 35.46$ & $1353.25^{b} \pm 36.16$ & $359.79 \pm 13.02^{b}$ & $3.17 \pm 0.10$ & $95.42 \pm 1.14$ \\
\hline RIR & $2223.00^{c} \pm 43.49$ & $2560.50^{c} \pm 45.14$ & $720.08^{c} \pm 22.25$ & $548.96^{c} \pm 21.32$ & $246.65 \pm 7.27^{c}$ & $3.21 \pm 0.12$ & $95.83 \pm 0.83$ \\
\hline \multicolumn{8}{|l|}{ Environment } \\
\hline Intensive & $4295.22^{a} \pm 370.69$ & $4993.37^{a} \pm 443.82$ & $2168.89^{a} \pm 311.61$ & $1697.46^{a} \pm 247.55$ & $360.33 \pm 26.00^{b}$ & $3.53^{a} \pm 0.06$ & $95.89 \pm 0.76$ \\
\hline Free range & $3199.00^{b} \pm 219.36$ & $3892.20^{\mathrm{b}} \pm 294.15$ & $1769.33^{b} \pm 225.79$ & $1297.85^{b} \pm 161.98$ & $376.51 \pm 25.88^{a}$ & $2.84^{b} \pm 0.07$ & $95.56 \pm 0.89$ \\
\hline \multicolumn{8}{|c|}{ Strain $\times$ environment interaction } \\
\hline $\mathrm{CFG} \times$ Intensive & $6051.50^{a} \pm 34.08$ & $7141.17^{a} \pm 47.92$ & $3867.67^{a} \pm 21.48$ & $3052.50^{\mathrm{a}} \pm 16.50$ & $504.55 \pm 5.15^{\mathrm{a}}$ & $3.75^{\mathrm{a}} \pm 0.04$ & $90.00 \pm 0.83$ \\
\hline CSG $\times$ Intensive & $4504.67^{c} \pm 33.56$ & $5165.28^{c} \pm 34.89$ & $1872.67^{c} \pm 35.68$ & $1444.67^{c} \pm 31.64$ & $320.91 \pm 8.39^{c}$ & $3.38^{b} \pm 0.09$ & $95.83 \pm 1.54$ \\
\hline RSG $\times$ Intensive & $2329.50^{\mathrm{e}} \pm 28.07$ & $2673.67^{e} \pm 30.50$ & $766.33^{e} \pm 30.39$ & $595.21^{\mathrm{e}} \pm 27.74$ & $255.54 \pm 11.48^{d}$ & $3.47^{b} \pm 0.11$ & $95.00 \pm 0.00$ \\
\hline$C F G \times$ free range & $4317.33^{b} \pm 35.71$ & $5405.50^{b} \pm 37.90$ & $2944.17^{b} \pm 31.53$ & $2129.00^{b} \pm 30.84$ & $493.08 \pm 4.96^{\mathrm{a}}$ & $2.61^{c} \pm 0.05$ & $95.00 \pm 1.29$ \\
\hline $\mathrm{CSG} \times$ free range & $3163.17^{d} \pm 42.36$ & $3823.78^{d} \pm 41.32$ & $1690.00^{d} \pm 30.15$ & $1261.83^{d} \pm 37.55$ & $398.67 \pm 8.44^{b}$ & $2.96^{d} \pm 0.12$ & $95.00 \pm 1.83$ \\
\hline $\mathrm{RSG} \times$ free range & $2116.50^{f} \pm 54.73$ & $2447.33^{f} \pm 53.98$ & $673.83^{\dagger} \pm 20.35$ & $502.71^{\dagger} \pm 19.35$ & $237.77 \pm 8.34^{d}$ & $2.95^{d} \pm 0.15$ & $96.67 \pm 1.67$ \\
\hline \multicolumn{8}{|l|}{$P$-values } \\
\hline Strain & $<.0001$ & $<.0001$ & $<.0001$ & $<.0001$ & $<.0001$ & 0.9263 & 0.0796 \\
\hline Environment & $<.0001$ & $<.0001$ & $<.0001$ & $<.0001$ & 0.0206 & $<.0001$ & 0.1392 \\
\hline Interaction & $<.0001$ & $<.0001$ & $<.0001$ & $<.0001$ & $<.0001$ & $<.0001$ & 0.1944 \\
\hline
\end{tabular}

a-f Within a column and effect, means with a common superscript do not differ with probability $P=0.05$

FI: feed intake, FBW: final bodyweight, WG: weight gain, FCE: feed conversion, GE: growth efficiency, LIV: liveability, CFG: commercial fast-growing, CSG: commercial slow-growing, RIR: Rhode Island Red 
Rearing environment had a significant impact on FBW of the birds. The intensive system had produced significantly heavier birds than the free-range system. Li et al. (2017) reported similar results, which indicated higher weight birds were produced in a more intensive environment than those produced in a free-range system with outdoor access. The increased growth in the intensive system could be because of the higher FI of the birds. Feed was not provided to free-range birds in the daytime and the birds were free to forage for food on their own. Unlike in the free-range system, intensively managed birds were dependent solely on commercial feeds that were available ad libitum. This might have created the big difference in $\mathrm{FI}$ between production systems and ultimately in the FBW. Additional factors such as temperature, photoperiod, and light intensity, which are season dependent and not controlled, may have affected the performance of extensively managed chickens and made their reaching market weight more difficult (Fanatico et al., 2005). However, contrary to the current findings, Chen et al. (2013) reported no difference in the growth performance of the birds reared indoors or free range.

Relative to the interaction, the CFG broiler strain had the highest WG and FBW in both rearing systems, followed by the CSG broilers and then by the RIR. These effects were larger (in units and proportionately) on the intensive system than on the free-range system.

There was a significant effect of strain on FCE (Table 3). Production system also exerted a significant impact on FCE in that the birds in a free-range system were more efficient compared with intensively reared birds. When the interaction of strains and production systems was evaluated, significant differences were noted in the FCE The CFG raised under intensive conditions were the most favourable, and when these birds were reared under free range, they were similarly efficient. The poorest FCE was noted for RIR reared under free range. This might be because these chickens were not subjected to genetic selection, whereas the fast-growing chickens were the result of a selection programme in which improved feed conversion ratio was one of the main selection criteria. The CSG presented significantly higher FCE when raised under freerange systems compared with intensive rearing. The performance gap between intensive and free-range CSG suggested that this genotype is better suited to a free range rather an intensive environment. Earlier, Berhe and Gous (2008) had shown significant differences in FCE of the CFG and Ross-788 strains, reporting more gain per unit of $\mathrm{FI}$ in females of CFG than males and females of Ross-788 broilers. Mikulski et al. (2011) reported comparable feed conversion ratios for different strains. However, Anderle et al. (2016) reported significantly better feed conversion ratio of intensively reared caged slow-growing chickens compared with those that had outdoor access and opportunities for grass consumption. Probably the difference from these findings was because of higher FI of intensive birds than free-range chickens. Because the birds under free range were not provided with commercial feed and were dependent solely on grazing and picking from the environment, this unrecorded FI might result in more weight gain per unit of measured FI.

The differences among strains in GE were not significant, but production system did have a significant impact on the GE of the birds (Table 3). Birds reared in the intensive system grew more relative to their initial weight than birds in the free-range system $(P<0.0001)$. Gondwe and Wolny $(2003)$ reported similar results in which Black Australorp chickens had better GE under an intensive system than in village rearing. This illustrates that technological advancements in poultry housing are more beneficial for the birds to show their growth potential. Under both production systems, the GE of CSG and RIR did not differ. However, the GE of the CFG broilers was improved under the intensive system relative to the free-range system where this strain was least efficient. Thus, the choice of a fast-growing genotype to rear under free range would not be viable. It would be better to raise slow-growing birds that perform similarly to commercial broilers. The results also suggested that CFG struggled to adapt to the free-range system, but that the CSG and RIR broilers were more adaptable to differences in production system.

Liveability did not differ $(P>0.05)$ due to differences in strains, rearing environments, and their interaction (Table 3). However, there was a tendency $(P<0.10)$ toward greater survival of the CSG and RIR broilers compared to the CFG broilers. Similar to the current findings, Ipek and Sozcu (2017) reported no differences in mortality that resulted from differences in genotype, production system, or in their interaction. However, in a previous study, liveability was affected significantly by rearing system with higher mortality rate in the indoor system than in an outdoor one (Zhao et al., 2014). In the current study, the similar liveability of the experimental strains and production systems could be attributed to the health care that was provided.

In the intensive system, the CFG broilers had the highest cost of production, followed by the same genotype in the free-range system. Cost of production was intermediate for the CSG broilers in both the intensive and free-range systems and lowest for the RIR in the free-range system. Feed cost and the price of day-old chicks were the two largest contributors to the total cost of production. The labour cost was higher in the free-range system because of the increased need for labour to manage it. Income from these birds was highest for the CFG broilers that were managed under the intensive system, followed by nearly comparable earnings from the CFG broilers in free range system and CSG in an intensive system. The lowest revenue 
was derived from RIR broilers that were raised in either the intensive or the free-range system. The slide in price/kg from light weights to heavier weights shrunk the differences in income per bird relative to the situation of constant unit pricing. Profit per bird was clearly maximized by the CSG broilers that were raised in a free-range system, making it the most suitable production system and genotype. The RIR broiler raised in the free-range system had the second highest profit/bird, whereas RIR and CSG broilers that were raised in the intensive system had equal and intermediate profits per bird. Although the CFG had the maximum earning per bird, the profit was lowest in this genotype and production system (Table 4).

Table 4 Economic evaluation of fast- and slow-growing broiler chickens reared in intensive and free-range production environments

\begin{tabular}{lcccccc}
\hline Broiler strain & \multicolumn{2}{c}{ Commercial fast growing } & \multicolumn{2}{c}{ Commercial slow growing } & \multicolumn{2}{c}{ Rhode Island Red } \\
\hline Production environment & Intensive & Free range & Intensive & Free range & Intensive & Free range \\
\hline Chick cost, \$ & 0.35 & 0.35 & 0.34 & 0.34 & 0.20 & 0.20 \\
Feed intake, kg/bird & 7.14 & 5.41 & 5.17 & 3.82 & 2.67 & 2.45 \\
Feed price /kg feed, \$ & 0.36 & 0.36 & 0.36 & 0.36 & 0.36 & 0.36 \\
Feed cost/bird, \$ & 2.58 & 1.95 & 1.86 & 1.38 & 0.96 & 0.88 \\
Litter cost /bird, \$ & 0.07 & 0.07 & 0.07 & 0.07 & 0.07 & 0.07 \\
Labour cost, \$ & 0.07 & 0.11 & 0.07 & 0.11 & 0.07 & 0.11 \\
Vaccination \& medication, \$ & 0.11 & 0.11 & 0.11 & 0.11 & 0.11 & 0.11 \\
Miscellaneous, \$ & 0.36 & 0.36 & 0.36 & 0.36 & 0.36 & 0.36 \\
Total input cost /bird, \$ & $\mathbf{3 . 5 4}$ & $\mathbf{2 . 9 5}$ & $\mathbf{2 . 8 2}$ & $\mathbf{2 . 3 7}$ & $\mathbf{1 . 7 7}$ & $\mathbf{1 . 7 3}$ \\
FBW at 56 days old, kg & 3.87 & 2.94 & 1.87 & 1.69 & 0.77 & 0.67 \\
Selling price, / $\mathbf{k g}$ FBW, \$ & 0.94 & 1.05 & 1.59 & 1.62 & 2.52 & 2.88 \\
Earnings /bird, \$ & $\mathbf{3 . 6 3}$ & $\mathbf{3 . 0 8}$ & $\mathbf{2 . 9 7}$ & $\mathbf{2 . 7 4}$ & $\mathbf{1 . 9 3}$ & $\mathbf{1 . 9 4}$ \\
Profit /bird, \$ & 0.09 & 0.13 & 0.16 & 0.37 & 0.16 & 0.22 \\
\hline
\end{tabular}

\section{Conclusion}

The physiological status and performance of broilers likely depends on the interaction of strain and environment. Thus, the choice of broiler strain should be conditioned on the production environment. Despite generally higher levels of performance, the profit from CFG broilers raised intensively was low compared with CSG and even RIR broilers raised in the free-range system.

\section{Authors' Contribution}

$\mathrm{JH}$ planned the experimental design and supervised the experiment. AG conducted the research, collected the data, and drafted the original report. AM worked on statistical analysis and assisted in interpretation of the results. MHJ assisted with revising and formatting of the manuscript.

\section{Conflict of Interest Declaration}

No authors have a conflict of interest relative to this work.

\section{References}

Ali, K.O., Katule, A.M. \& Syrstad, O., 2000. Genotypexenvironment interaction in growing chickens: Comparison of four genetic groups on two rearing systems under tropical conditions. Acta Agric. Scand. A Anim. 50(2), 65-71.

Batool, T., Farooq, S., Roohi, N., Mahmud, A., Usman, M., Ghayas, A. \& Ahmad, S., 2018. Effect of different dietary lysine regimens on meat quality attributes in varieties of indigenous aseel chicken Yerel Aseel. Kafkas Univ. Vet. Fak. Derg. 24(5), 639-645.

Bell, D.D. \& Weaver, W.D. (eds.), 2002. Commercial chicken meat and egg production. Springer Science \& Business Media, LLC. New York, USA. pp. 46-48.

Bennett, C.E., Thomas, R., Williams, M., Zalasiewicz, J., Edgeworth, M., Miller, H., Coles, B., Foster, A., Burton, E.J. \& Marume, U., 2018. The broiler chicken as a signal of a human reconfigured biosphere. R. Soc. Open Sci. 5(12), 180325.

Berhe, E.T. \& Gous, R.M., 2008. Effect of dietary protein content on growth, uniformity and mortality of two commercial 
broiler strains. S. Afr. J. Anim. Sci. 38(4), 293-302.

Branciari, R., Mugnai, C., Mammoli, R., Miraglia, D., Ranucci, D., Dal Bosco, A. \& Castellini, C., 2009. Effect of genotype and rearing system on chicken behavior and muscle fiber characteristics. J. Anim. Sci. 87(12), 4109-4117.

Cangar, Ö., Aerts, J.M., Buyse, J. \& Berckmans, D., 2008. Quantification of the spatial distribution of surface temperatures of broilers. Poult. Sci. 87(12), 2493-2499.

Chabault, M., Baéza, E., Gigaud, V., Chartrin, P., Chapuis, H., Boulay, M., Arnould, C., D’Abbadie, F., Berri, C., \& Le Bihan-Duval, E., 2012. Analysis of a slow-growing line reveals wide genetic variability of carcass and meat quality-related traits. BMC Genet. 13(1), 90.

Chen, X., Jiang, W., Tan, H.Z., Xu, G.F., Zhang, X.B., Wei, S. \& Wang, X.Q., 2013. Effects of outdoor access on growth performance, carcass composition, and meat characteristics of broiler chickens. Poult. Sci. 92(2), 435-443.

Cömert, M., Şayan, Y., Kirkpinar, F., Bayraktar, H. \& Mert, S., 2016. Comparison of carcass characteristics, meat quality, and blood parameters of slow and fast grown female broiler chickens raised in organic or conventional production system. Asian-Aust. J. Anim. Sci. 29(7), 987.

Cook, M.E., 2000. Skeletal deformities and their causes: Introduction. Poult. Sci. 79(7), 982-984.

Da Silva, D.C.F., de Arruda, A.M.V. \& Gonçalves, A.A., 2017. Quality characteristics of broiler chicken meat from freerange and industrial poultry system for the consumers. J. Food Sci. Technol. 54(7), 1818-1826.

Damane, M.M., Barazandeh, A., Mokhtari, S.M., Esmaeilipour, O. \& Badakhshan, Y., 2018. Evaluation of body surface temperature in broiler chickens during the rearing period based on age, air temperature and feather condition. Iran. J. Appl. Anim. Sci. 8(3), 499-504.

Damme, K., Keppler, C., Hausleitner, M., Bachmeier, J., Hartmann, J., Louton, H. \& Rauch, H.E., 2015. Test of different premium broiler genotypes under animal welfare label conditions. Part I: Fattening and slaughter yield. Arch. fur Geflugelkd. 79.

Etches, R.J., John, T.M. \& Gibbins, A.M.V., 2008. Behavioural, physiological, neuroendocrine and molecular responses to heat stress. In N.J. Daghi (ed). Poultry production in a hot climate. Second edition. CABI, Wallingford, UK. pp. 31-66.

Fanatico, A.C., Pillai, P.B., Cavitt, L.C., Owens, C.M. \& Emmert, J.L., 2005. Evaluation of slower-growing broiler genotypes grown with and without outdoor access: Growth performance and carcass yield. Poult. Sci. 84(8), 3121-1327.

Gondwe, T.N. \& Wollny, B.A., 2003. Comparative productivity of Black Australorp and indigenous chicken under freeranging village conditions in Malawi. Proc. Conf. Int. Agric. Res. Devel., 8-10 October. Göttingen, Germany. pp. 17.

Harash, G., Richardson, K.C., Alshamy, Z., Hünigen, H., Hafez, H.M., Plendl, J. \& Masri, S.A.I., 2019. Heart ventricular histology and microvasculature together with aortic histology and elastic lamellar structure: A comparison of a novel dual-purpose to a broiler chicken line. PLoS One. 14(3), e0214158.

Hassanzadeh, M., Gilanpour, H., Charkhkar, S., Buyse, J. \& Decuypere, E., 2005. Anatomical parameters of cardiopulmonary system in three different lines of chickens: Further evidence for involvement in ascites syndrome. Avian Pathol. 34(3), 188-193.

Hiemstra, S.J. \& Napel, J.T., 2013. Study of the impact of genetic selection on welfare of chicken bred and kept for meat production. Final report of a project commissioned by the European Commission. IBF International Consulting, Brussels, Belgium.

Hoan, D. \& Khoa, M.A., 2016. Meat quality comparison between fast growing broiler Ross 308 and slow growing Sasso laying males reared in free range system. J. Sci. Devel. 14(1), 101-108.

Hussain, M., Mahmud, A., Hussain, J., Qaisrani, S.N., Mehmood, S. \& Rehman, A., 2018. Subsequent effect of dietary lysine regimens fed in the starter phase on the growth performance, carcass traits and meat chemical composition of aseel chicken in the grower phase. Rev. Bras. Cienc. Avic. 20(3), 455-462.

Ipek, A. \& Sozcu, A., 2017. The effects of access to pasture on growth performance, behavioural patterns, some blood parameters and carcass yield of a slow-growing broiler genotype. J. Appl. Anim. Res. 45(1), 464-469.

Julian, R.J., 2000. Phsiological management and environmental triggers of the ascites syndrome: A review. Avian Pathol. 29(6), 519-527.

Karcher, D.M. \& Mench, J.A., 2018. Overview of commercial poultry production systems and their main welfare challenges. In: Mench J.A., (ed). Advances in Poultry Welfare. Elsevier, Amsterdam, The Netherlands. pp. 3-25.

Khawajaa, T., Khanb, S.H., Mukhtara, N., Ali, M.A., Ahmed, T. \& Ghafar, A., 2012. Comparative study of growth performance, egg production, egg characteristics and haemato-biochemical parameters of Desi, Fayoumi and Rhode Island Red chicken. J. Appl. Anim. Res. 40(4), 273-283.

Koomkrong, N., Theerawatanasirikul, S., Boonkaewwan, C., Jaturasitha, S. \& Kayan, A., 2015. Breed-related number and size of muscle fibres and their response to carcass quality in chickens. Ital. J. Anim. Sci. 14(4), 41-45.

Li, H., Wen, X., Alphin, R., Zhu, Z. \& Zhou, Z., 2017. Effects of two different broiler flooring systems on production performances, welfare, and environment under commercial production conditions. Poult. Sci. 96(5), 1108-1119.

Machida, N. \& Aohag, Y., 2001. Electrocardiography, heart rates, and heart weights of free-living birds. J. Zoo Wildl. Med. 32, 47-54.

McNab, B.K., 1966. An analysis of the body temperatures of birds. Condor 68(1), 47-45.

Mikulski, D., Celej, J., Jankowski, J., Majewska, T. \& Mikulska, M., 2011. Growth performance, carcass traits and meat quality of slower-growing and fast-growing chickens raised with and without outdoor access. Asian-Aust. J. Anim. Sci. 24(10), 1407-1416.

Muller, H.D. \& Carroll, M.E., 1966. The relationships of blood pressure, heart rate and bodyweight to aging in the domestic fowl. Poult. Sci. 45(6), 1195-1198. 
Mutibvu, T., Chimonyo, M. \& Halimani, T.E., 2017. Physiological responses of slow-growing chickens under diurnally cycling temperature in a hot environment. Rev. Bras. Cienc. Avic. 19(4), 657-576.

National Chicken Council., 2017. National Chicken Council calls for balance between animal care, environmental, economic impact in chicken production. https://www.nationalchickencouncil.org/national-chicken-council-callsbalance-animal-care-environmental-economic-impact-chicken-production/ Accessed 20 December 2019.

Olkowski, A.A., 2007. Pathophysiology of heart failure in broiler chickens: Structural, biochemical, and molecular characteristics. Poult. Sci. 86(5), 999-1005.

Richards, S.A., 1971. The significance of changes in the temperature of the skin and body core of the chicken in the regulation of heat loss. J. Physiol. 216(1), 1-10.

Sadef, S., Khan, M.S. \& Rehman, M.S., 2015. Indigenous chicken production in Punjab: A detailed survey through participatory rural appraisals. J. Anim. Plant Sci. 25(5), 1273-1282.

Thaxton, Y., Christensen, K.D., Mench, J.A., Rumley, E.R., Daugherty, C., Feinberg, B., Parker, M., Siegel, P. \& Scanes, C.G., 2016. Symposium: Animal Welfare Challenges for Today and Tomorrow. Poult. Sci. 95, 21982207.

Thornton, G., 2016. The expanding market for slow growing broilers, WATTAgNet article No. 28132. http://www.wattagnet.com/articles/28132-the-expanding-market-for-slow-growingbroilers?v=preview_Accessed on 20 December 2019.

Tickle, P.G., Hutchinson, J.R. \& Codd, J.R., 2018. Energy allocation and behaviour in the growing broiler chicken. Sci. Rep. 8(1), 4562.

Yahav, S., Shinder, D., Tanny, J. \& Cohen, S., 2005. Sensible heat loss: The broiler's paradox. World's Poult. Sci. J. 61(3), 419-434.

Younis, M., ElEdel, M., Nasr, S., Mahrous, U. \& Aboghanima, M., 2016. Response of Cobb and Sasso broilers to feeding restriction and tryptophan supplementation. Alexandria J. Vet. Sci. 51(1), 127-134.

Zhao, Z.G., Li, J.H., Li, X. \& Bao, J., 2014. Effects of housing systems on behaviour, performance and welfare of fastgrowing broilers. Asian-Aust. J. Anim. Sci. 27(1), 140-146. 